\title{
Dynamic wireless charging of electric vehicles on the move with Mobile Energy Disseminators
}

\author{
Leandros A. Maglaras \\ School of Computer Science and Informatics \\ De Montfort University, Leicester, UK
}

\author{
Jianmin Jiang \\ Department of Computing \\ University of Surrey, Guilford, UK
}

\author{
Athanasios Maglaras \\ Electrical Engineering Department \\ T.E.I. of Thessaly, Larissa, Greece
}

\author{
Frangiskos V. Topalis \\ Electrical and Computer Engineering Department \\ N.T.U.A., Athens, Greece
}

\author{
Sotiris Moschoyiannis \\ Department of Computing University \\ of Surrey, Guilford, UK
}

\begin{abstract}
Dynamic wireless charging of electric vehicles (EVs) is becoming a preferred method since it enables power exchange between the vehicle and the grid while the vehicle is moving. In this article, we present mobile energy disseminators (MED), a new concept, that can facilitate EVs to extend their range in a typical urban scenario. Our proposed method exploits InterVehicle (IVC) communications in order to eco-route electric vehicles taking advantage of the existence of MEDs. Combining modern communications between vehicles and state of the art technologies on energy transfer, vehicles can extend their travel time without the need for large batteries or extremely costly infrastructure. Furthermore, by applying intelligent decision mechanisms we can further improve the performance of the method.
\end{abstract}

Index Terms-Electric vehicle; Dynamic Wireless Charging; IVC; Cooperative Mechanisms

\section{INTRODUCTION}

With regards to the future transport arena, electric vehicles $(E V s)$ are considered as the likely replacement of internal combustion engine driven vehicles, especially given the $\mathrm{CO}_{2}$ reduction and alternative energy perspectives. Electric cars have the potential to reduce carbon emissions, local air pollution and the reliance on imported oil [1]. In Europe, the European commission aims to reduce road transport emissions by $70 \%$ by 2050 [2]. Taking into account the fact that road transport is expected to double by 2050, passenger cars need to reduce their emissions significantly. Advanced internal combustion engine (ICE) technologies are expected to enable emissions reduction, but are not expected to meet long term targets. Electric vehicles, especially plug-in ones (PEVS), are penetrating the market and they are currently counted as zero emissions vehicles. Apart from the additional cost of their lithium-ion battery pack that makes them more expensive than conventional vehicles, there are also some other factors that discourage drivers from switching to an $E V$. For instance, electric battery vehicles have a limited driving distance [3] and hence, the current lack of charging infrastructure as well as the total time needed to recharge such a vehicle add to their lack of desirability.

\section{MOTIVATION : INCREASING A CAR'S ALL-ELECTRIC RANGE}

In order to surmount this problem, industries and research institutions around the world have proposed numerous solutions. These vary from stationary stations that are scattered across the road network in central positions [4], [5], [6], dynamic wireless charging methods that take advantage of the mobility of nodes [7], [8] and eco-routing algorithms that run in isolation in every vehicle or in a central way for a fleet of vehicles [9], [10], [11]. Dynamic wireless charging is gaining more ground, since it enables power exchange between the vehicle and the grid while the vehicle is moving. Installed infrastructure can be utilized very effectively because many vehicles use the same road segments that are "equipped" with dynamic charging capabilities. Dynamic charging can take place in a parking lot, at a bus stop during passenger disembarkation, along a highway or near traffic lights.

\section{A. Wired charging}

Electric vehicles are plugged for charging on the existing electrical grid infrastructure, but sometimes the electrical infrastructure is inadequate for supporting this additional energy demand of high power fast charging stations. Moreover, the presence of several concurrent charging requests could cause overload conditions in local nodes of the grid, if the charging processes of the PEVs are not properly managed and scheduled. One alternative to fast charging stations [4] is to have mobile charging systems (MCSs) with a high storage Capacity and a mobile charging system for electric vehicles is presented in [12]. These stations can be a solution when the electrical infrastructure of the local grid is unable to support high power fast charging stations.

Smart scheduling strategies can be profitably used to manage the $(P E V)$ charging problem [5], for based on quadratic programming for charging $P E V s$, these can decrease the peak load and flatten the overall load profile. The usage of Information and Communication Technology (ICT) in a smart grid environment is a proposed solution [13], [14]. Regarding 
which, the authors in [15] advocate the deployment of smart grid communication architectures by using small embedded systems in a hierarchical way or a manner that can enable the distribution grid to charge a large number of $E V s$ without the need to carry a high workload.

\section{B. Dynamic wireless charging}

Dynamic wireless charging is gaining more ground, since it enables power exchange between the vehicle and the grid while the vehicle is moving.

Recently, the Telewatt project introduced an original approach involving the reusing of existing public lighting infrastructures for such charging, whereby a fraction of the power not consumed by lamps at night can be used for the benefit of the charging stations. The service is accessible by a smartphone application, where clients specify to the TeleWatt server their destination and their battery level, for which they receive a response of a list of available charging terminals close to this destination [6]. Hevo announced a novel dynamic charging system where manhole covers will be used as charging stations and a pilot program is scheduled to be performed in New York in 2014. Two Online Electric Vehicle $(O L E V)$ buses that can charge during travel have been put into service for the first time in the world on normal roads in the city of Gumi - Korea by the Korea Advanced Institute of Science and Technology (KAIST) [7]. The power is transmitted through magnetic fields embedded in the roads. That is, it comes from the electrical cables buried under the surface of the road, thus creating these magnetic fields and the length of power strips installed is generally $5 \%-15 \%$ of the entire road. In [16] the authors present a method for power transfer between electric vehicles, where drivers "share" charge with each other using the inductive power transfer (IPT) of the charge between vehicles at rendezvous points. However, one major issue with this concept is the technology requirements that have to be met by passenger vehicles in order for this solution to be feasible. Moreover, the dynamic charging of vehicles raises health issues related to the leaking magnetic flux from IPT.

\section{The charging station location problem}

Thoughtful siting of public charging stations can ease consumer range anxiety while offering a lower cost approach to integrating $E V s$ into the transportation market. The authors in [17] propose a method to anticipate parking demands and more efficiently to locate $E V$ charging infrastructure in new settings and/or subject to different constraints. The researchers in [18] used Lisbon, Portugal, as a case study where they determined not just the locations to be installed, but also their capacity of at each location, with the aim of optimizing the demand covered within an acceptable level of service. In [11], the authors try to build a comprehensive objective function taking into account geographic information, construction cost and running cost in order to achieve optimal planning of charging stations. In [19] an electric vehicle battery swapping station is described as well as a business case scenario provided where customers have access to the stations such that they can meet their motion energy requirements by swapping batteries for charged ones quite quickly.

\section{Eco-routing of EVs}

Similar to eco-routing for conventional vehicles, novel methods are being developed and used in order to reduce the energy consumption of EVs [9], [20]. The authors in [9] have developed an eco-routing navigation system, which determines the most eco-friendly route between a trip's origin and its destination. With the use of a Dynamic Roadway Network database that integrates historical and real time data they managed to reduce $\mathrm{CO}_{2}$ emissions. Based on their previous work they now aim to create an eco-routing algorithm that will be incorporated into a prototype eco-routing navigation system forEVs. In [20], they moved a step further by creating a routing system that could extend the driving range of $E V s$ by calculating the minimum energy route to a destination.

\section{E. Contributions}

The present article develops a cooperative mechanism for dynamic wireless charging of electric vehicles and makes the following contributions:

- The concept of mobile energy disseminators is introduced

- A cooperative mechanism based on inter-vehicular communications (IVC) and long term evolution (LTE) communication is proposed

- A route optimization problem for every electric vehicle is formulated

- The proposed mechanism is evaluated through extensive simulations

The rest of this paper is organized as follows: Section III describes the concept of mobile energy disseminators ( $M E D$ ) and in Section IV the communication mechanisms are presented. In Section V the optimization problem is formulated, whilst Section VI presents the simulation environment And the results. Section VII concludes the article.

\section{MOBILE ENERGY DISSEMINATORS}

Energy exchange can be facilitated by inductive power transfer (IPT) between vehicles and/or by installing a roadside infrastructure unit for wireless charging. However, given the vast expanse of road networks, it is impractical to have infrastructure units on every road segment due to prohibitive costs. IPT allows efficient and real-time energy exchange where vehicles can play an active role in the energy exchange procedure. On the other hand, the use of mobile nodes as relay nodes is common in vehicular ad hoc networks (VANETs). In a VANET mobile relay nodes can serve as carriers and disseminators of useful information. Influential spreaders, nodes that can disseminate the information to a large part of the network effectively, are an open issue in ad hoc networks. That is, nodes with predefined or repeating routes that can cover a wide range of a city region can do the work of roadside units while exploiting their mobility in order to provide higher quality-of-service $(Q o S)$. 


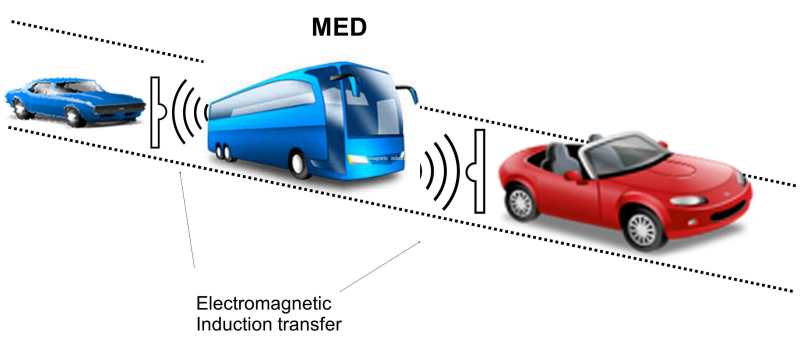

Fig. 1. Electromagnetic induction transfer

Similar to information dissemination, special nodes, like buses (trucks), can act as energy sources to $E V s$ that need charging, in order to increase travel time. These vehicles, form now on called mobile energy disseminators $(M E D s)$, use electric plug in connection or IPT in order to refill starving EVs. Buses can play the role of MEDs since they follow predefined scheduled routes and their paths cover a major part of a city, while trucks could have the role of energy chargers mainly on highways. Buses can be fully charged when parked, before beginning their scheduled trip, and can be continuously charged along their journey by IPT stations installed at bus stops. Additional technology requirements that these vehicles may need in order to operate as energy sources, is an open issue, but it is rather more feasible in the near future, to have these features installed into large public vehicles than into passenger vehicles due to the additional cost and space requirements. Vehicles that book charging places on the same $M E D$ can create clusters and mobile charging stations will play the role of the clusterheads.

The vehicle requiring electric charge will approach the appropriate truck, after a preceding agreement, from the rear or the front end depending on the vehicle construction. The procedure will provide vehicle charging by an electric plug in connection (or process), or by electromagnetic induction with the use of Tesla coils. Immobilized charging can take place at predetermined road points (for example parking areas) in order to avoid traffic obstruction and in this case the method of the plug in electric connection is preferable. A synchronization of the vehicles' movement will be executed via wireless communication mainly controlled by the truck/bus. From the analysis undertaken, it is apparent that it is preferable, for reasons of safety and better management of the system, that the vehicle needing charge should move ahead or behind the truck creating a cluster [21], [22] or platoon [23]. There will be a special joint magnetic arrangement concerning the vehicles, as well as a special interlocking arrangement in order for the two vehicles to approach and remain in contact, even while in motion, for as long as the charge transfer takes place. Charge transfer can be achieved with electric plug in connection, or by electromagnetic induction. During the latter transfer, the charge and consequently the power transfer will be accomplished with the use of two detached subsystems of magnetic coupling of high efficiency.

The electromagnetic subsystems will include magnetic coils, which will cooperate and function like the primary and the secondary coils of a transformer, which will have loose coupling using air as the proper medium. This way of coupling (like Tesla coils) has proven to be more efficient than using ferromagnetic materials. The primary coil of the truck will be movable and able to be inserted in the bigger diameter coil of the vehicle, in order to improve the efficiency factor of the power transfer process and to minimize the leaking of magnetic flux. Moreover, the two subsystems will be specially shielded (Faraday cage) in order to protect occupants and bystander vehicles or pedestrians from electromagnetic radiation. The truck/bus will carry high capacity batteries and if needed, the appropriate electric system to convert voltage from $D C$ to $A C$ voltage of high frequency. It will also need to carry a conventional internal combustion engine in addition to the correct electric generator, to be used to produce electric energy in an emergency situation.

The advantages of the proposed system are a) high efficiency factor (especially when the charge transfer is achieved via an electrical plug in connection) b) very short delay regarding the moving of the vehicles c) significant reduction of environmental pollution and d) coverage of special needs in exceptional climatic conditions or failure conditions.

\section{Cooperative mechanisms}

By using cooperative mechanisms, based on dedicated short-range communication (DSRC) capabilities of vehicles or long term evolution (LTE) technology, vehicles search for the MEDs in range and arrange a charging appointment while moving [8]. In the following section, we present a cooperative mechanism, based on the $(D S R C)$ and $L T E$ capabilities of vehicles. A network $G=(N, L)$, where $N$ is the set of nodes (intersections) and $L$ is the set of links (road segments), is considered. $V$ is the set of electric vehicles that move in the network and $\mathrm{M}$ is the subset of electric vehicles that can act as mobile charging stations.

\section{A. IVC system}

In order to state its presence, each $M E D$ periodically broadcasts cooperative awareness messages $(C A M)$. Each beacon message consists of a node identifier $\left(V_{i d}\right)$, node location, scheduled trip (a subset of set $L$ ), current charging capability $(C C)$ and energy value $(E / K W h) . C C$ is the current energy that the mobile charging station can afford to dispose of to charge the vehicle without jeopardizing its own needs. These messages are disseminated by all vehicles that act as relay nodes.

Each $E V$ that needs energy, upon receiving a $C A M$ by an $M E D$ performs the following steps:

1) Checks whether $M E D$ is on his route or not according to their current positions and destinations

2) Checks whether the $C C$ level is high enough in order to cover its energy needs

3) Asks for a charging place by sending a $C A M$ which contains minimum charging time 

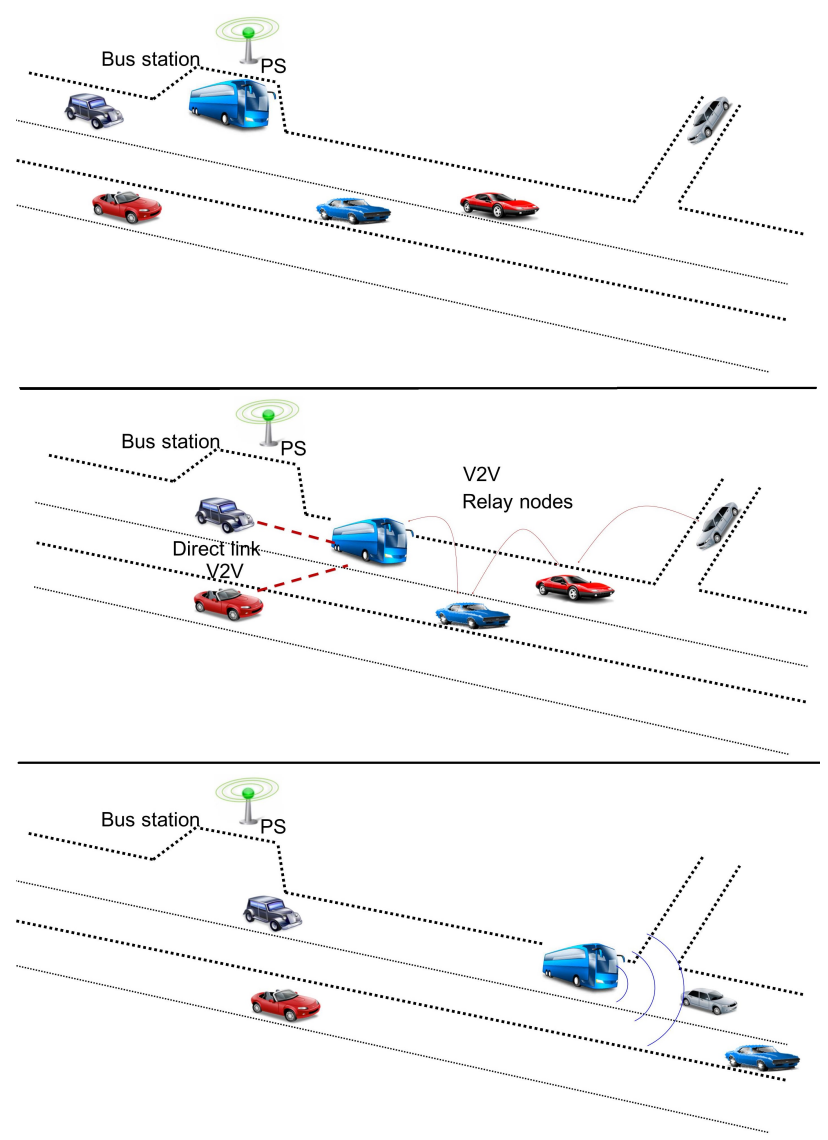

Fig. 2. Application example of a mobile energy disseminator: A. Contactless charging is used to deliver charging to a bus B. V2V communication between MED and EV C. EV recharges from the bus using IPT

4) Chooses to select this bus as the wireless energy transfer station

5) Books a charging place

6) Drives in front of or behind the bus for the determined time period in order to recharge

Steps 3-5 constitute the negotiation phase, in which $M E D$ and $E V$ exchange dedicated short range messages $(D S R C)$ in order to confirm the energy transfer. An assumption that we make is that vehicles can book their charge of battery as soon as they realize that their charge level is low and a $M E D$ meets their criteria on relative distance and available energy. The architecture of the proposed mobile energy dissemination is demonstrated in Figure 2.

\section{B. LTE system}

For the $L T E$ system, we assume that vehicles are equipped with The Evolved Universal Terrestrial Radio Access Network (EUTRAN) interface, which enables the vehicles to communicate with the $e N B$ so as to access the core components of the LTE. LTE Evolved Node B $(e N B)$ base station transceivers are deployed alongside the road network in order to cover the area. Each bus communicates to the LTE the scheduled trip that is going to be followed, the available

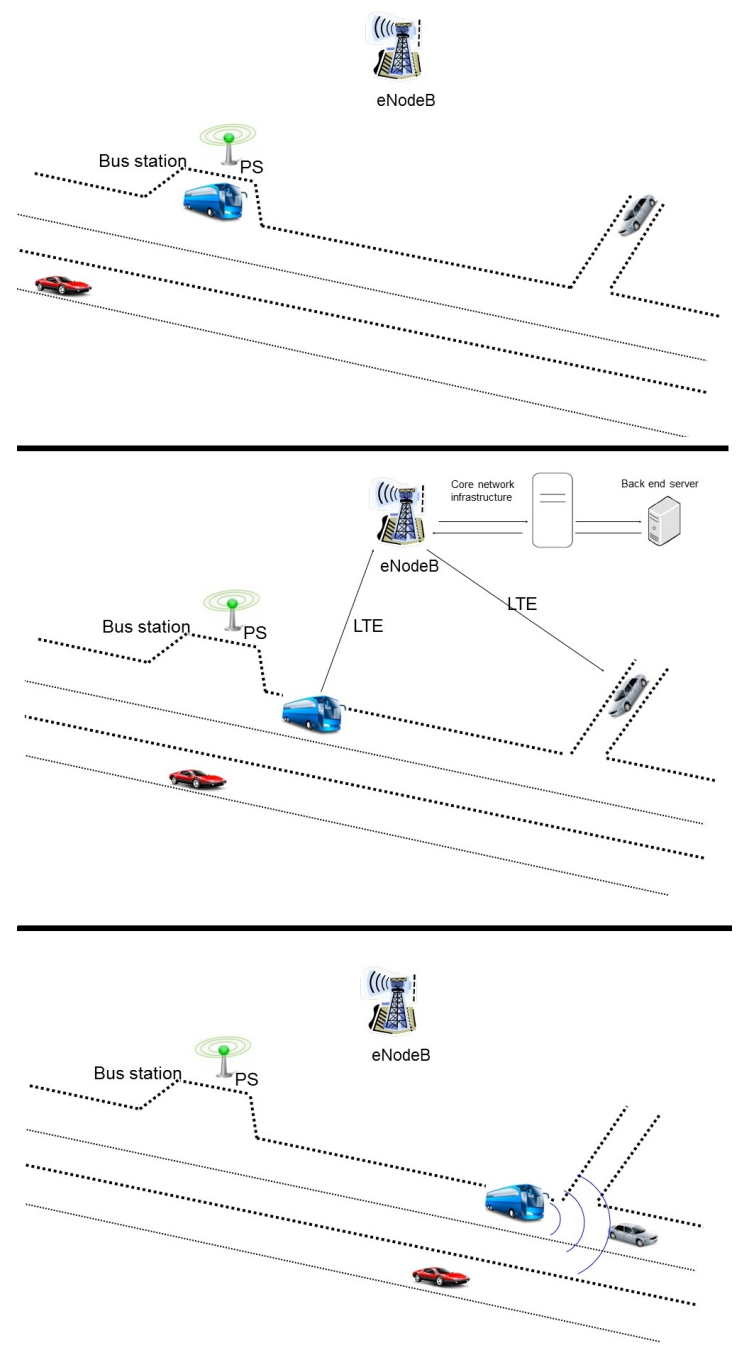

Fig. 3. Application example of Mobile Energy Disseminator: A. Contactless charging is used to deliver charging to a bus B. LTE communication between $M E D$ and $E V$ C. Electric vehicle recharges from the bus with inductive power transfer $(I P T)$

charging capability and energy value and charging availability, similar to the $I V C$ system. All vehicles are assumed to be equipped with $G P S$.

Each EV that needs energy:

1) Checks whether $M E D$ is on his route or not according to their current positions and destinations

2) Checks whether the $C C$ level is high enough in order to cover its energy needs

3) Checks whether the $M E D$ is already fully booked

4) Books a charging place

5) Drives along the bus for the determined time in order to recharge

The architecture of the proposed mobile energy dissemination architecture is demonstrated in Figure 3. The benefits of such an approach are threefold: First, it utilizes existing cellular infrastructure. Second, the 802.11pnetwork overhead introduced by frequent communication between $E V s$ and 

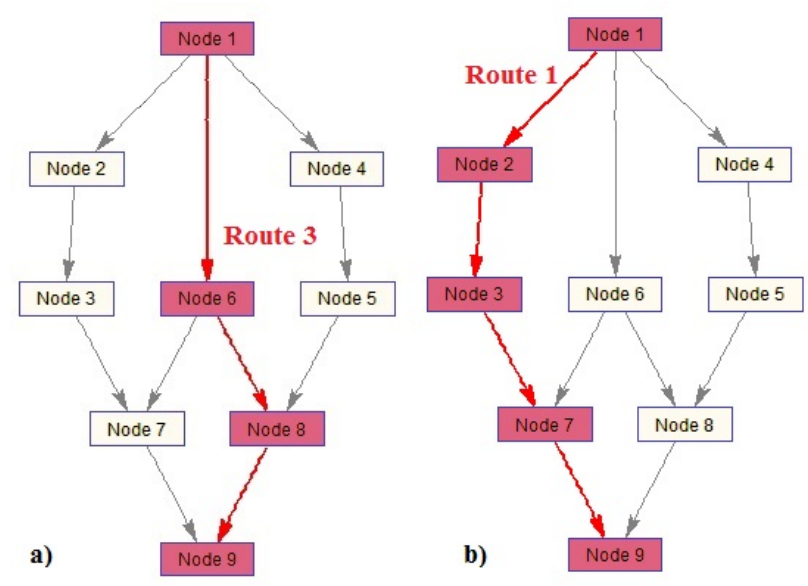

Fig. 4. Optimum path selection based on a) Distance (Route 3), b) Time (Route 1)

$M E D s$ is offloaded. Third, information is more up to date than that received through $I V C$, where many intermediate relay nodes may be needed in order to disseminate data effectively. However, vehicles are required to have two types of network interface cards. Moreover packets that pass through the $L T E$ core potentially experience more delay.

Route selection algorithms, where vehicles communicate with each other in order to exchange information are crucial in order to evaluate the performance of the method. Optimal route selection overcomes a common problem in which all vehicles are preferring the same paths, leading to over congestion. Optimal routing of vehicles that use this new technology can be formulated as a modified shortest-path problem where the weights of the road segments may vary over time, according to the existence or not of a $M E D$ traveling on the road segment [24].

\section{FORMULATION OF THE METHOD}

Vehicle routing aims at identifying a feasible route that satisfies metrics constraints. These metrics are associated with multiple parameters which can include delay, distance and energy cost. Mathematical formulation of vehicle routing is intrinsically the restricted shortest path problem (RSP). In order to test the performance of the method we solve an optimization problem where an objective function that combines time, distance and power is used in order to make the best route selection. The optimization problem is solved in isolation for each vehicle based on whether the road segments include $M E D s$, the additional distance that the vehicles have to travel and the predicted travel time to the destination. A simple graph is shown in Figure 4, where a vehicle has to choose between four routes, one containing a $M E D$ and three one of which being the shortest path in terms of distance

The optimization problem for each vehicle $i$ is formulated:

$$
\min \sum_{j k} W_{i j k}, \text { where } W_{i j k}=F\left(E_{i j k}, T_{i j k}, D_{i j k}\right)
$$

s.t.

$$
\begin{gathered}
\sum_{j k} T_{i j k} \leq T_{t h} \\
\sum_{j k} D_{i j k} \leq D_{t h} \\
\sum_{j k} E_{i j k} \leq E_{o}+E_{i n d}
\end{gathered}
$$

where, $W_{i j k}$ is the weight assigned to each road segment $j k$ of the route of vehicle $i . E_{i j}$ is the energy that is being consumed on road segment $j k, E_{o}$ is the initial energy of vehicle and $E_{\text {ind }}$ is the induced energy to the vehicle $i$. Constraints (2) and (3) are used in order to avoid sending all vehicles from routes that are too long, which would lead to excessive cost in terms of time and distance of the trip. $T_{t h}, D_{t h}$ are parameters that give the upper limit of the overall time and the distance that a vehicle can spend in order to reach its destination. The energy cost of every road segment can be expressed as a proportion of the mean velocity. The velocity is the quotient of the distance of the road segment and the time that the vehicle will need to spend on this segment, on average. The two forces that oppose the motion of an automobile are rolling friction, $F_{\text {roll }}$ and air resistance, $F_{\text {air }}$.

$$
F_{\text {roll }}=\mu_{\tau} * m * g, F_{\text {air }}=\frac{1}{2} A * C * p * u^{2}
$$

where, $m$ is the mass of the car in $K g, g=9.8 m / s^{2}, u$ is the mean velocity in $\mathrm{m} / \mathrm{s}$ and $\mu_{\tau}$ is the rolling resistance coefficient. $C$ is a dimensionless constant called the drag coefficient that depends on the shape of the moving body, $A$ is the silhouette area of the car $\left(\mathrm{m}^{2}\right)$ and $p$ is the density of the air (about $1.2 \mathrm{~kg} / \mathrm{m}^{3}$ at sea level at ordinary temperatures). Typical values of $C$ for cars range from 0.35 to 0.50 .

In constant-speed driving on a level road, the sum of $F_{\text {roll }}$ and $F_{\text {air }}$ must be just balanced by the forward force supplied by the drive wheels. The power that a vehicle needs when traveling with a steady speed is given by Equation 6 .

$$
P=\eta * F_{\text {Forward }} * u=\eta\left(F_{\text {roll }}+F_{\text {air }}\right) * u
$$

,$\eta$ is the efficiency factor of the system.

The energy cost of vehicle $\mathrm{i}$ for traveling in road segment $(j), E_{i j}$, is calculated by Equation 7 .

$$
E_{i j}=P * T_{i j k}
$$

If the road segment belongs to the path of a $M E D$, then the vehicle can increase its energy by induction. The amount of the induced energy is proportional to the total time that the $E V$ and the $M E D$ will stay connected. This time depends on the meeting point between the vehicle and the $M E D$ in relation to the total road segment length and the availability of the $M E D$. In order to represent the induced energy to the electric vehicle Equation 7 is rewritten: 


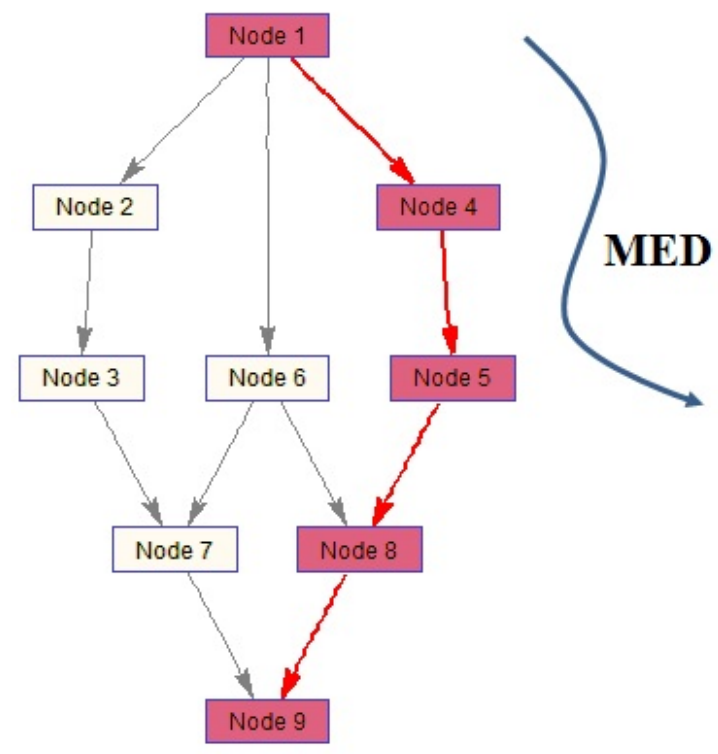

Fig. 5. Optimum path selection based on energy (Route 4)

$$
E_{i j k}=P * T_{i j k}-E_{i n d}
$$

where, $E_{\text {ind }}$ is given by:

$$
E_{\text {ind }}=t_{\text {cont }} * C_{\text {ind }} * P_{\text {ind }}
$$

$C_{i n d}$ is the induction coefficient and $t_{\text {cont }}$ the time of contact between the $M E D$ and the $E V . P_{i n d}$ is the power of the $M E D$. We ignore acceleration and deceleration phenomena. The edge parameters for the example network of Figure 4 are shown in Table I. The mean energy induced from a $M E D$ to a vehicle is calculated according to Equation 9 and the hypothesis that all vehicles that traverse the right part of the graph can be in contact with the $M E D$ throughout the time that it takes in order to traverse each road segment. Time of contact between the $M E D$ and $E V$ is calculated according to the length of the road segment $D_{j k}$ and the velocity of the $M E D, u_{\text {med }}$ (See Equation 10).

$$
t_{\text {cond }}=\sum_{j k \in P^{\prime}} \frac{D_{j k}}{u_{m e d}}
$$

Where, $P^{\prime}$ is the path that $M E D$ and $E V$ share, and it is constituted by individual road segments.

For the simulated scenario presented in Figures 4 and 5, Table I presents edge parameters. By comparing columns of time, distance and energy cost, it is obvious that the overall cost of each road segment is different according to the evaluation metric used. In the table, the optimum route for every single parameter (time, distance and energy) is highlighted and it is obvious that for the trip from node 1 to node 9 the optimal route in terms of energy consumption, without the existence of a $M E D$, is Route 3 (Nodes: 1, 6,
TABLE I

CALCULATION OF DISTANCE, TIME AND ENERGY COST FOR EVERY ROAD SEGMENT AND ROUTE

\begin{tabular}{|c|c|c|c|c|c|c|}
\hline $\begin{array}{c}\text { Road } \\
I D\end{array}$ & $\begin{array}{c}\text { Dist } \\
(\mathrm{Km})\end{array}$ & $\begin{array}{c}\text { Time } \\
(\mathrm{min})\end{array}$ & $\begin{array}{c}\text { Vel } \\
(\mathrm{Km} / \mathrm{h})\end{array}$ & $\begin{array}{c}\text { E cost } \\
(\mathrm{kWh})\end{array}$ & $\begin{array}{c}\text { E ind } \\
(\mathrm{kWh})\end{array}$ & $\begin{array}{c}\text { Total E } \\
(\mathrm{kWh})\end{array}$ \\
\hline 12 & 8 & 17 & 28.24 & 1.315 & 0.00 & 1.315 \\
\hline 24 & 8 & 24 & 20.00 & 1.315 & 1.200 & 0.114 \\
\hline 16 & 20 & 67 & 17.91 & 3.286 & 0.000 & 3.286 \\
\hline 23 & 12 & 17 & 42.35 & 1.972 & 0.000 & 1.972 \\
\hline 37 & 12 & 17 & 42.35 & 1.972 & 0.000 & 1.972 \\
\hline 45 & 12 & 33 & 21.82 & 1.972 & 1.800 & 0.172 \\
\hline 58 & 16 & 33 & 29.09 & 2.629 & 1.200 & 1.429 \\
\hline 67 & 12 & 25 & 28.00 & 1.972 & 0.000 & 1.972 \\
\hline 68 & 8 & 30 & 16.00 & 1.314 & 0.000 & 1.314 \\
\hline 79 & 4 & 17 & 14.12 & 0.657 & 0.000 & 0.657 \\
\hline 89 & 6 & 33 & 10.91 & 0.986 & 0.000 & 0.986 \\
\hline \hline Route & & & & & & \\
\hline 1 & 36 & $\mathbf{6 8}$ & & 5.920 & & 5.920 \\
\hline 2 & 36 & 109 & & 5.920 & & 5.920 \\
\hline 3 & $\mathbf{3 4}$ & 130 & & 5.587 & & 5.587 \\
\hline 4 & 42 & 123 & & 6.920 & 4.200 & $\mathbf{2 . 7 0 2}$ \\
\hline
\end{tabular}

$8,9)$. In the presence of a $M E D$ that travels road segments $(1,4),(45)$ and part of road segment $(58)$ the energy cost of Route 4 (Nodes: 1, 4, 5, 8,9) decreases, thus making it the optimal route

The objective function can be any combination of the parameters time, distance and energy. Using a linear combination with different weights $\left(w_{i}\right)$ per parameter (see Equation 11) is a solution that produces satisfactory outcomes and can be tuned in order to favour time, distance, energy or any combination of the parameters, according to the preferences of the driver.

$$
W_{i j k}=w_{1} *\left|E_{i j k}\right|+w_{2} *\left|T_{i j k}\right|+w_{3} *|D i j k|
$$

The road segments that comprise the routes that each vehicle can follow are:

- Route 1: Nodes $(1,2,3,7,9)$

- Route 2: Nodes $(1,6,7,9)$

- Route 3: Nodes $(1,6,8,9)$

- Route 4: Nodes $(1,4,5,8,9)$

\section{Vi. Method evaluation}

In order to evaluate the effect of the routing method to the $E V$ total range we conducted simulations where vehicles are injected into the road network. Vehicles choose their path according to distance, time and energy cost. In addition, the vehicles entering the system have initial energy according to a uniform distribution and the energy of each is measured when it reaches node 9 (exit node). All nodes are equipped with GPS receivers and On Board Units (OBU) and the location information of all vehicles/nodes, needed for the clustering algorithm, is collected with the help of the receivers. The only communications paths available are via the ad-hoc network and there is no other communication infrastructure. The power of the antenna is $P_{t x}=18 \mathrm{dBm}$ and the communication frequency $f$ is $5.9 \mathrm{Ghz}$. In our simulations, we use a minimum sensitivity $\left(P_{t h}\right)$ of $-69 \mathrm{dBm}$ to $-85 \mathrm{db}$, which gives a transmission range of 130 to 300 meters. 
TABLE II

MINIMUM SENSITIVITY IN RECEIVER ANTENNA ACCORDING TO DATA RATE.

\begin{tabular}{|c|c|}
\hline Data Rate $(\mathrm{Mb} / \mathrm{sec})$ & Minimum Sensitivity $(\mathrm{dBm})$ \\
\hline 3 & -85 \\
\hline 4.5 & -84 \\
\hline 6 & -82 \\
\hline 9 & -80 \\
\hline 12 & -77 \\
\hline 18 & -70 \\
\hline 24 & -69 \\
\hline 27 & -67 \\
\hline
\end{tabular}

TABLE III

SIMULATION PARAMETERS

\begin{tabular}{|c|c|c|}
\hline Independent parameter & Range of values & Default value \\
\hline \hline Number of MEDs & $1-2$ & 1 \\
\hline Number of vehicles & $50-100$ & 100 \\
\hline Initialenergy & $4-24 \mathrm{~kW}$ & $24 \mathrm{~kW}$ \\
\hline MED capacity & $1-2$ & 2 \\
\hline$C_{\text {ind }}$ & $0.7-0.8$ & 0.8 \\
\hline$P_{\text {ind }}$ & $20-50 \mathrm{~kW}$ & $40 \mathrm{~kW}$ \\
\hline$\eta$ & $0.7-0.8$ & 0.8 \\
\hline$E_{t h}$ & $6-10 \mathrm{~kW}$ & $6 \mathrm{~kW}$ \\
\hline Vehicle rate $($ eh $/ \mathrm{min})$ & $1 / 5-1 / 15$ & $1 / 5$ \\
\hline Parameters $w_{1}, w_{2}, w_{3}$ & $0-1$ & $1 / 3$ \\
\hline
\end{tabular}

The arrival rate of the vehicles follows the Poison process with parameter $\lambda$ and the speed assigned to them is associated with the speed limit of each road segment. The range of values is given in Table III. Each $M E D$ moves in circles representing the path that a bus follows during a day in the city and each vehicle in need of energy sends its query using a broadcast mode. Each $M E D$ that receives the query replies with its availability according to the procedure described in subsection IV-A. In the case where a vehicle receives more than one reply from different $M E D s$, it decides which to choose according to the objective function 11 and the values of the weights $w_{i}$. Each $M E D$ stores the received applications and final decisions from the EVs along with the unique $I D$ that each vehicle has.

In the upcoming subsections, each figure represent a snapshot of a simulated scenario except for figures 11, 17, 18 and 19 as well as tables IV and VI, where the mean values of the outcomes of 100 different simulations are represented.

\section{A. Network with one MED}

In the first evaluation scenario, we simulate the network of Figure 5, where only one $M E D$ exists. Vehicles decide to follow the energy efficient, time efficient or the distance efficient path (shortest path), according to the policy of the driver. Based on this policy, the weights $w_{1}, w_{2}, w_{3}$ assigned to time, distance and energy are different and the vehicles follow different paths.

The induced energy to the vehicles that traverse road segments $(12,45$, and 58) is given by Equation 9. It is worth mentioning that in all the simulated scenarios the vehicles wait at the beginning of the road segment until the $M E D$ approaches the intersection so as to achieve maximum contact time. Therefore, the vehicles choose to wait for the $M E D$ to arrive even if it is not near and once in contact accept a longer path as necessary. This behaviour may lead to some vehicles having additional energy consumption, due to longer trip in terms of time. Moreover, this situation, where vehicles wait in the beginning of the area when a $M E D$ is moving, induces additional parameters in the routing algorithm, e.g. waiting cost that is translated into additional energy cost, time cost and additional total load in the network due to stationary cars. In the simulation environment $M E D s$ have the capability of charging up to two vehicles simultaneously and they ignore any incoming calls for charging when they are fully booked. The simulation parameters are given in Table III.

1) Energy efficient scenario: In this case, each vehicle $V_{i}$ that enters the simulation area, decides upon the optimal route based on an energy threshold, which can be derived from Equation 4. If initial energy is below $6 \mathrm{~kW}$, which is the maximum amount needed in order to reach the destination (node 9), the vehicle asks the $M E D$ for an empty induction slot, which has two places of charging. If it has an empty slot then $V_{i}$ books it and waits for the $M E D$ to reach node 1 in order to begin recharging (Route 4). In the case where the initial energy of the vehicle is above threshold or no free charging place exists, it chooses to follow the shortest path in terms of distance (Route 3). Each $M E D$ is driving on a ring road which consists of road segments (14), (45), part of road segment (58) and other roads out of our simulation area of the same distance. The $M E D$ is driving at a velocity that is $90 \%$ of the maximum for the road segment, whilst the EVs travel at $100 \%$ of the allowed speed limit. When a vehicle $V_{i}$ follows a $M E D$ for recharging its velocity drops to the latter's velocity.

In Figure 6, we observe the energy consumption of each vehicle during its travel in the simulation area. Vehicles enter the simulation area with a random initial energy between 4 and $24 k W$. Vehicles with low initial energy, book a free charging place on the $M E D$ and manage to lower the consumed energy in the area.

Vehicles that choose to recharge during their travel in the simulation area need to wait for the $M E D$ to reach node 1 . Bearing in mind that $M E D$ is following a different route, which includes road segments outside of the simulated area, and the current position of the $M E D$ at the time that the booking application happens, the vehicle calculates the waiting time and decides whether to wait or not for the $M E D$. In this scenario vehicles do not have any time threshold, and wait no matter how long the time may be, as long as the $M E D$ has a free charging place. This additional waiting time is represented in Figure 7.

When a vehicle $V_{i}$ follows the $M E D$ in order to recharge, in addition to more time this choice leads to a greater distance having to be traveled. This additional distance is represented in Figure 8.

2) Impact of the time threshold: In this scenario, vehicles with energy below the threshold $(6 \mathrm{~kW})$ decide to recharge only 


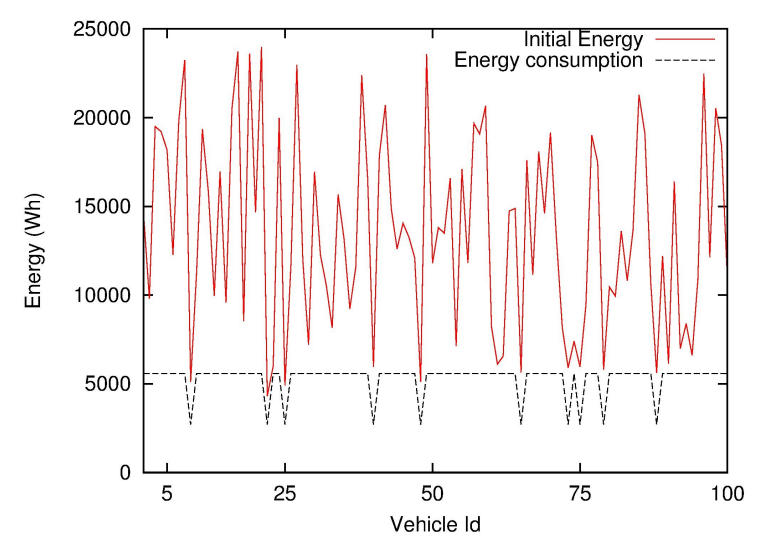

Fig. 6. Energy consumption of Vehicles

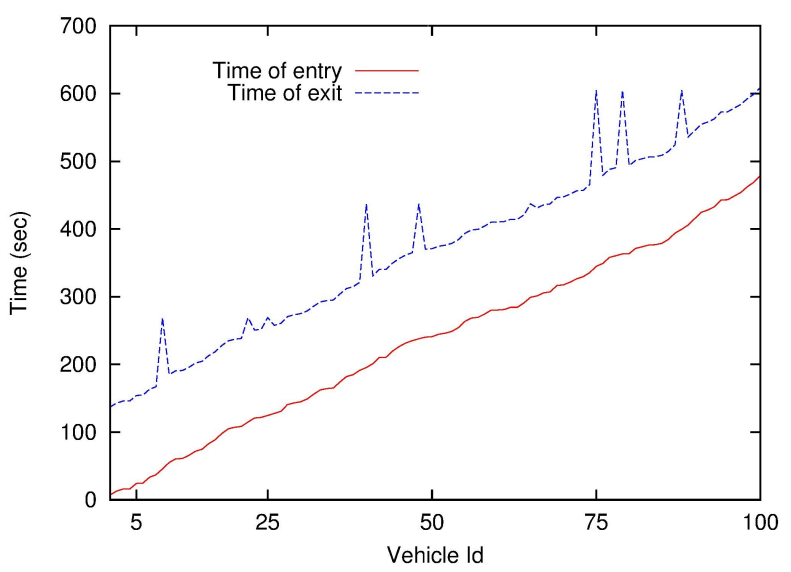

Fig. 7. Travel time of vehicles

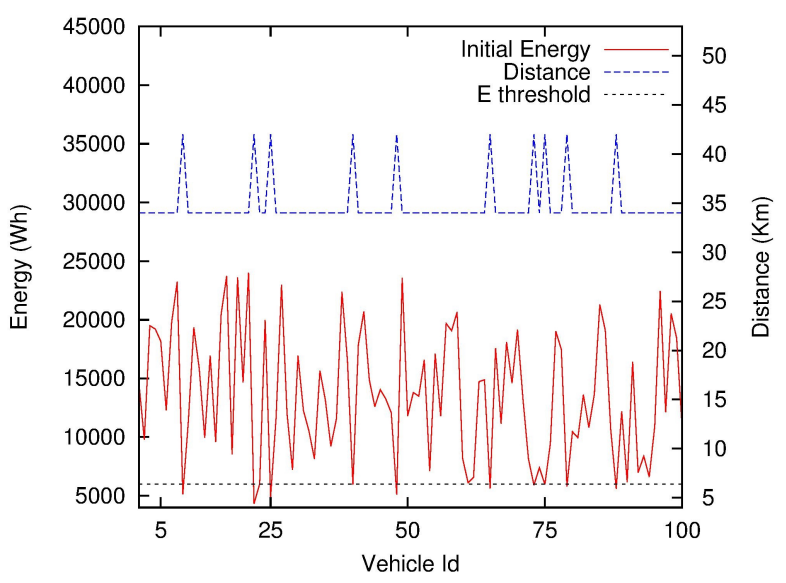

Fig. 8. Distance covered by every vehicle in the simulation scenario

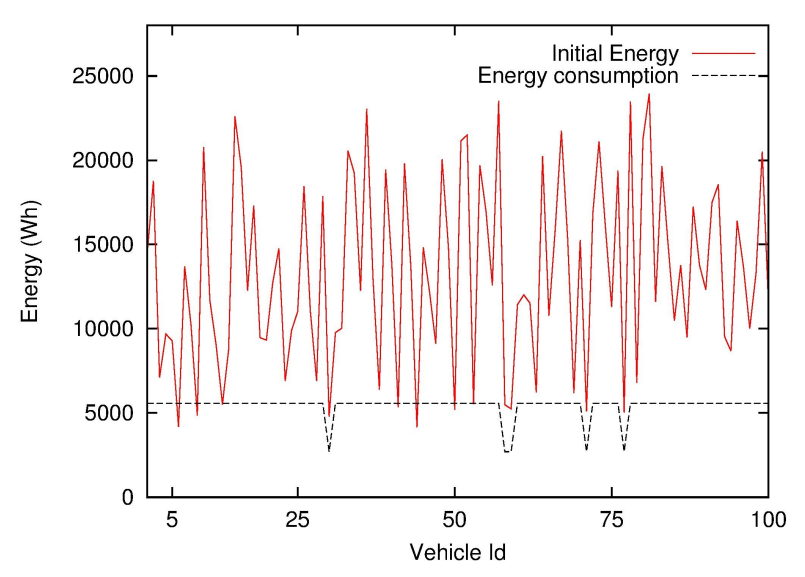

Fig. 9. Energy consumption of vehicles with time threshold

if this procedure is not going to induce too much additional travel time and in order to achieve this, every has its own maximum wait time for the $M E D$. When recharge is needed, a vehicle calculates the required wait time and if total travel time does not exceed the time threshold then it chooses to recharge (Route 4). Conversely, if the total travel time exceeds the time threshold, the vehicle decides to follow the shortest path in terms of distance (Route 3) and the effects of this policy on energy are depicted in Figure 9. In the simulations conducted the time threshold is assigned a value that is the same as the time that a $M E D$ needs in order to perform a circle. It is assured that each vehicle waits for the $M E D$ to complete at most one circle until it reaches the initial point of charge (Node 1). In the case when the approaching $M E D$ has no empty charging spot, the vehicles do not wait for another circle to be completed and follow the shortest path and it is assumed that they find a stationary charging spot along their way in order to refill.

3) Impact of E threshold: Increasing the energy threshold causes an increase in the demands for recharging from starving vehicles. Since $M E D$ has a limited capacity (in this experiment the capacity of the $M E D$ has the default value 2), large energy thresholds will not have any positive effects on the overall performance of the system. Vehicles will either need to wait for longer times or will not be able to find a free charging place (Figures 10,11). If a $M E D$ has an empty slot, then $V_{i}$ books it and waits for the former to reach node 1 in order to begin recharging (Route 4). In the case that the initial energy of vehicle is above threshold or no free charging place exists, it chooses to follow the shortest path in terms of distance (Route 3).

We can observe in 10 , that vehicle 25 enters the area with low energy, but since no free charging place is available on the $M E D$ it runs out of power and the same happens with vehicles 65,73 and 88 . Increasing the threshold but keeping the number of charging places to the default value of 2 , which is the feasible scenario, the number of vehicles that can be served does not increase. At the same time, vehicles with no 


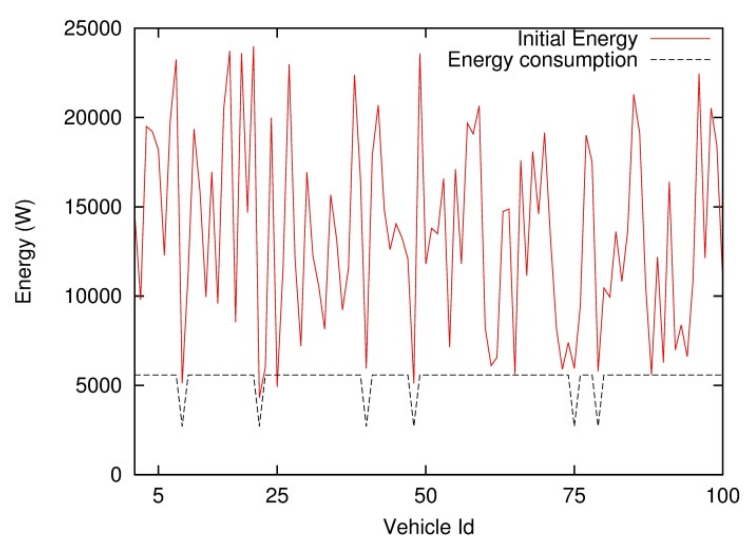

Fig. 10. Energy consumption of vehicles. $M E D$ with 2 charging places, Energy threshold $6 \mathrm{~kW}$

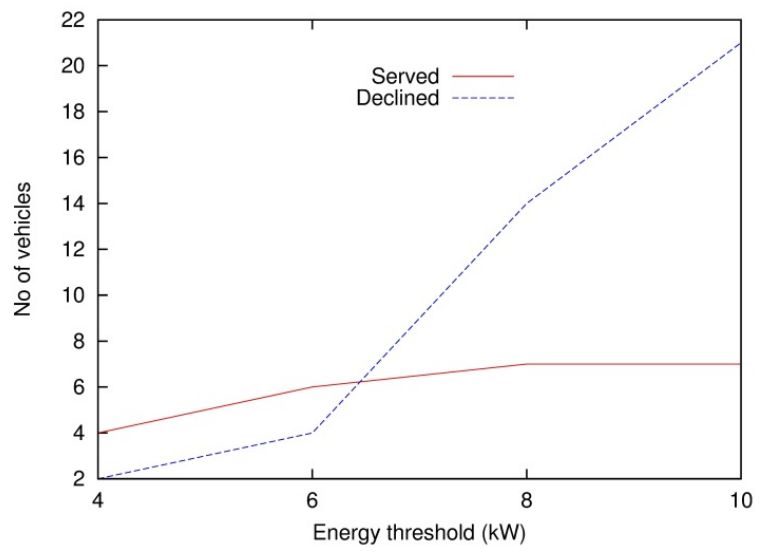

Fig. 11. An increase in the energy threshold leads to more requests for charging and since $M E D s$ capacity is limited most requests are declined.

immediate need for energy may occupy a charging place, thus leaving out vehicles that are starving (Figure 11).

4) Impact on the vehicles' total range: The initial purpose of the method is to increase the mean total range of electric vehicles. Based on the above scenarios, we can deduce that since the energy of starving vehicles is protected the mean total range of every vehicle of the investigated system will also increase. In order to visualize this effect, we extract the remaining energy of all the vehicles after they reach node 9 and compare it with that rmaining if they all followed the shortest or the fastest path.

In Figure 12, we present the remaining energy of every vehicle after reaching node 9 and it can be seen that only one runs out of energy before reaching its destination, when using the energy optimal efficient scenario. That is, this vehicle does not manage to find an empty place for charging on the $M E D$ and the initial energy that it had was not sufficient for it to reach its destination. In the shortest path and fastest time scenarios the number of vehicles that run out of energy

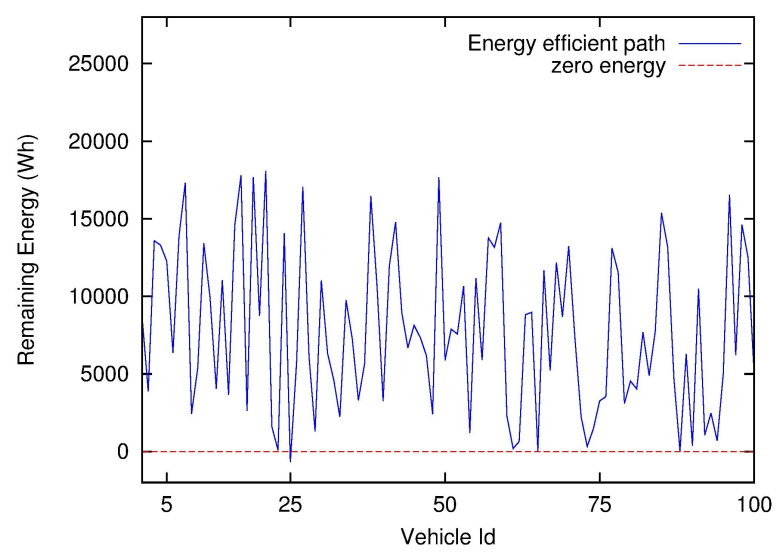

Fig. 12. Remaining energy of vehicles when reaching destination node 9

TABLE IV

EVALUATION OF PERFORMANCE BASED ON REMAINING ENERGY $E$ OF VEHICLES AFTER HAVING REACHED TARGET NODE 9.

\begin{tabular}{|c|c|c|c|}
\hline Method & $\begin{array}{c}\text { No of Vehicles with } \\
\text { with } E_{\text {out }}<0\end{array}$ & $\begin{array}{c}\text { Mean } E_{\text {out }} \\
\mathrm{kWh}\end{array}$ & $\begin{array}{c}\text { Additional } \\
\text { range \% }\end{array}$ \\
\hline \hline Energy path & 1 & 10.096 & \\
\hline Shortest path & 4 & 9.072 & $-11.3 \%$ \\
\hline Fastest path & 9 & 7.044 & $-43.3 \%$ \\
\hline
\end{tabular}

and have to stop before reaching the final destination is given in Table IV. The same table also shows the mean value of the remaining energy. It is evident that the energy efficient scenario, based on the use of $M E D s$, gives better outcomes and balances the consumed energy of the vehicles.

Based on the remaining energy, we can easily find the total additional range that each vehicle can travel and in fact, $M E D s$ manage to increase the total range of each vehicle in a typical urban scenario by as much as 43.3

\section{B. Network with two MEDS}

In the second evaluation scenario the network we use is the one from Figure 13. The graph includes a second $M E D$ that induces further added distance to a vehicle that chooses to follow it. Vehicles decide to follow the energy efficient, the time efficient or the distance efficient path (shortest path) according to the policy of the driver.

The new added route 5 comprises the nodes $(1,2,10,11,7,9)$.

1) Energy efficient path: If the initial energy of a vehicle is below $6 \mathrm{~kW}$, which is the maximum amount of energy needed in order to reach its destination, it asks both $M E D s$ for an empty energy induction slot. Each $M E D$ has two places for charging. If one has an empty slot, then $V_{i}$ books this slot and waits for the $M E D$ to reach the closest node in order to begin recharging (Route 4 or Route 5). In case that the initial energy of vehicle is above threshold or no free charging place exists, vehicle chooses to follow the shortest path in terms of distance (Route 3).

In Figure 14, we observe the energy consumption of each vehicle during its travel in the simulation area. Vehicles enter 


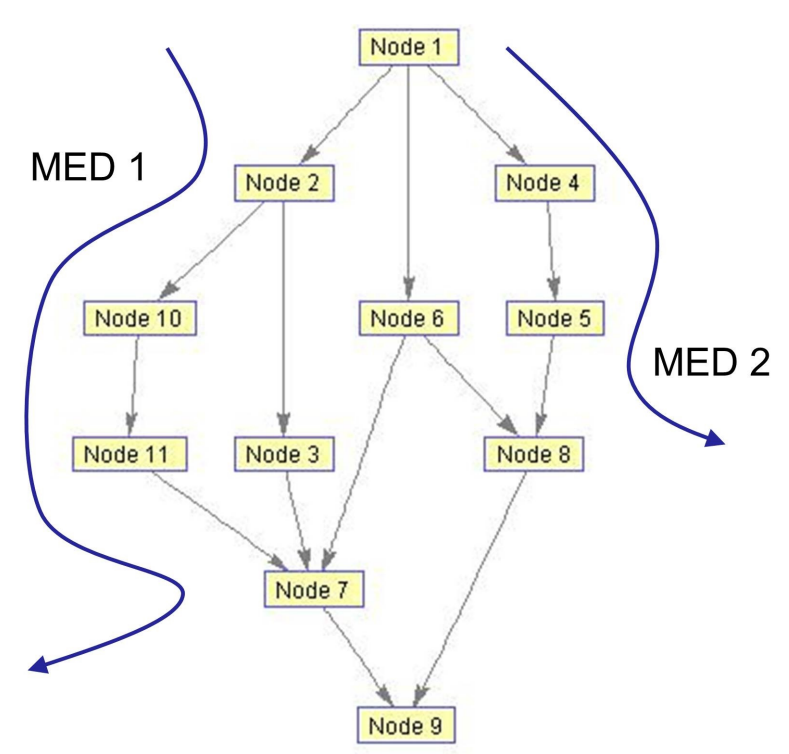

Fig. 13. Network topology with two MEDs

TABLE V

CALCULATION OF DISTANCE, TIME AND ENERGY COST FOR EVERY ROAD SEGMENT AND ROUTE FOR THE 2ND SIMULATION SCENARIO (FIGURE 13).

\begin{tabular}{|c|c|c|c|c|c|c|}
\hline $\begin{array}{c}\text { Road } \\
I D\end{array}$ & $\begin{array}{c}\text { Dist } \\
(\mathrm{Km})\end{array}$ & $\begin{array}{c}\text { Time } \\
(\mathrm{min})\end{array}$ & $\begin{array}{c}\text { Vel } \\
(\mathrm{Km} / \mathrm{h})\end{array}$ & $\begin{array}{c}\text { E cost } \\
(\mathrm{kWh})\end{array}$ & $\begin{array}{c}\text { E ind } \\
(\mathrm{kWh})\end{array}$ & $\begin{array}{c}\text { Total E } \\
(\mathrm{kWh})\end{array}$ \\
\hline 12 & 8 & 17 & 28.24 & 1.315 & 0.00 & 1.315 \\
\hline 14 & 8 & 24 & 20.00 & 1.315 & 1.200 & 0.114 \\
\hline 16 & 20 & 67 & 17.91 & 3.286 & 0.000 & 3.286 \\
\hline 23 & 12 & 17 & 42.35 & 1.972 & 0.000 & 1.972 \\
\hline 37 & 12 & 17 & 42.35 & 1.972 & 0.000 & 1.972 \\
\hline 45 & 12 & 33 & 21.82 & 1.972 & 1.800 & 0.172 \\
\hline 58 & 16 & 33 & 29.09 & 2.629 & 1.200 & 1.429 \\
\hline 67 & 12 & 25 & 28.00 & 1.972 & 0.000 & 1.972 \\
\hline 68 & 8 & 30 & 16.00 & 1.314 & 0.000 & 1.314 \\
\hline 79 & 4 & 17 & 14.12 & 0.657 & 0.000 & 0.657 \\
\hline 89 & 6 & 33 & 10.91 & 0.986 & 0.000 & 0.986 \\
\hline 210 & 16 & 40 & 24.00 & 2.629 & 2.400 & 2.629 \\
\hline 1011 & 16 & 40 & 24.00 & 2.629 & 2.400 & 2.629 \\
\hline 117 & 16 & 40 & 24.00 & 2.629 & 2.400 & 2.629 \\
\hline \hline Route & & & & & & \\
\hline 1 & 36 & $\mathbf{6 8}$ & & 5.920 & & 5.920 \\
\hline 2 & 36 & 109 & & 5.920 & & 5.920 \\
\hline 3 & $\mathbf{3 4}$ & 130 & & 5.587 & & 5.587 \\
\hline 4 & 42 & 123 & & 6.920 & 4.200 & $\mathbf{2 . 7 0 2}$ \\
\hline 5 & 60 & 154 & & 9.202 & 7.200 & $\mathbf{2 . 0 0 2}$ \\
\hline
\end{tabular}

the simulation area with a random initial energy between 4 and $24 k W$. Vehicles with low initial energy book a free charging place in any of the two $M E D s$ and hence, manage to lower the consumed energy in the area.

Vehicles that choose to recharge during their travel in the simulation area need to wait for the $M E D$ at initial node where the recharging phase can begin. Bearing in mind that each $M E D$ is following a different route that includes road segments outside of the area and the current position of the $M E D$ at the time the booking application happens, the vehicle calculates the waiting time and decides whether to wait or not for the $M E D$. In this scenario, vehicles do not have any time threshold, and wait no matter how long the time may be as long as the $M E D$ has a free charging place. This additional

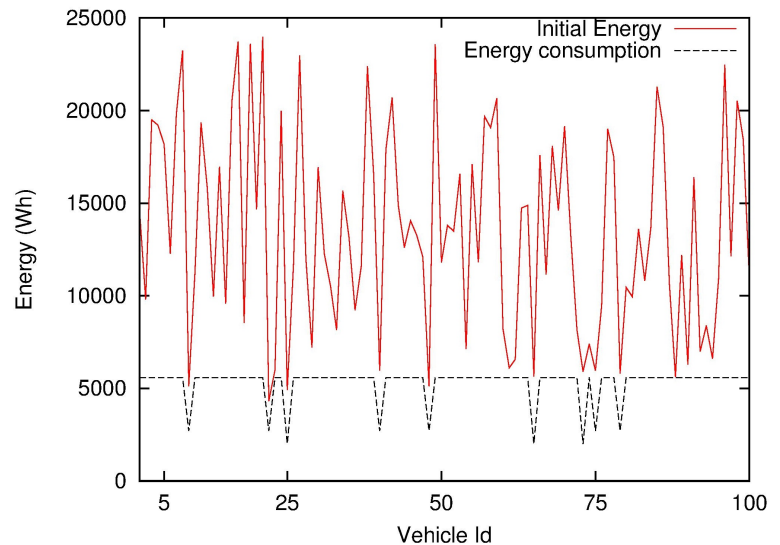

Fig. 14. Energy consumption of vehicles

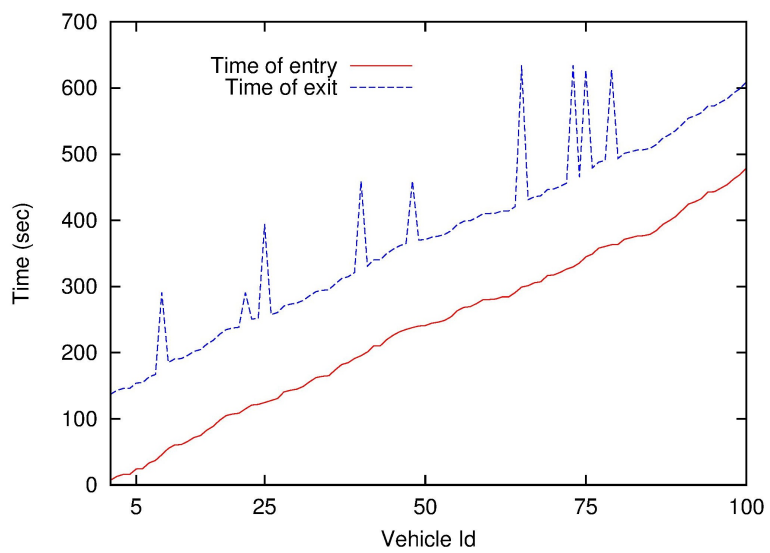

Fig. 15. Travel time of vehicles

waiting time is represented in Figure 15.

When vehicle $V_{i}$ follows any of the two $M E D s$ in order to recharge, in addition to more time, greater distance is traveled. The additional distance varies according to the $M E D$ that the vehicle chooses to follow, which is represented in Figure 16.

2) Impact of $E$ threshold: Increasing the energy threshold causes an increase in demand for recharging from starving vehicles. However with the addition of a second $M E D$ in this situation, although leads to an increase in vehicles demanding to be recharged, this can be covered. Nevertheless, the system still has a maximum capacity based on the availability of the $M E D$. If a $M E D$ has an empty slot, then $V_{i}$ books it and waits for the $M E D$ to reach node 1 in order to begin recharging (Route 4 or Route 5). In the cases where the initial energy of the vehicle is above the threshold or no free charging place exists, it chooses to follow the shortest path in terms of distance (Route 3).

3) Density of vehicles: Changing the density of vehicles that move through the simulated area affects the performance of the system. For instance, lowering the density makes it 


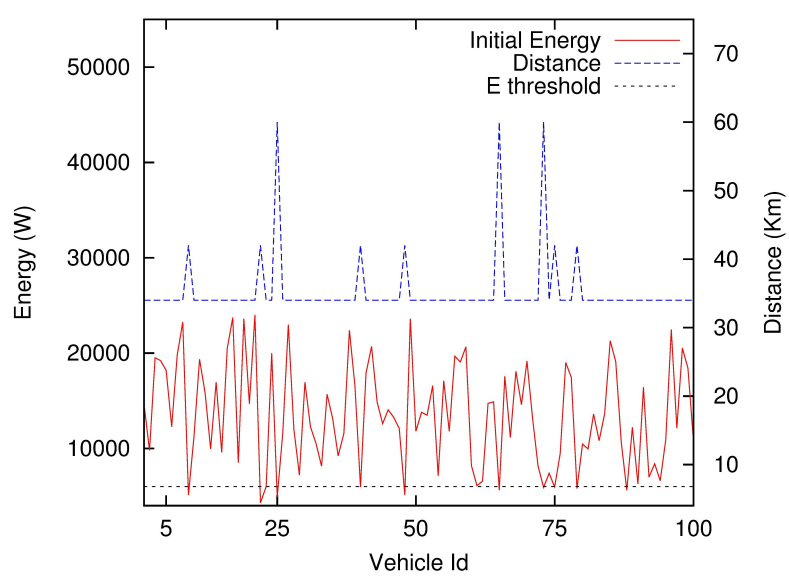

Fig. 16. Distance covered by every vehicle in the 2 nd simulation scenario

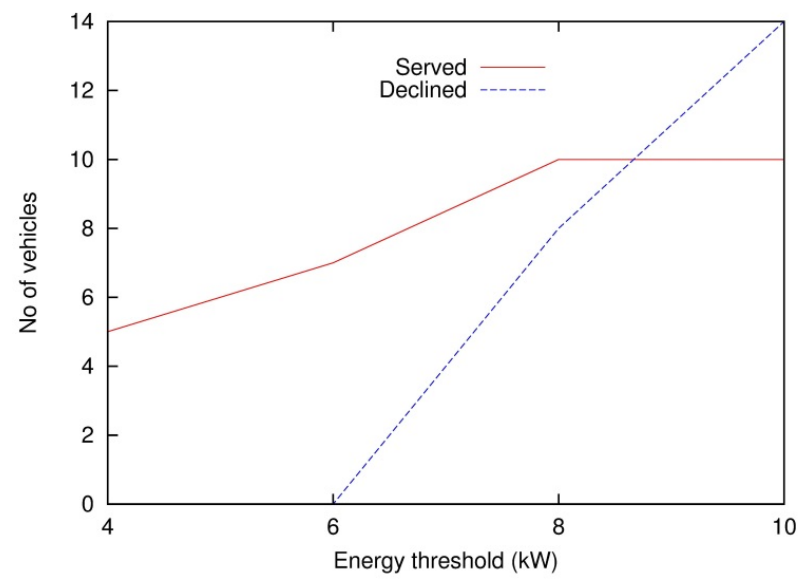

Fig. 17. System with $2 M E D s$ can serve an excessive number of requests

capable of dealing with more demands for charging and hence, efficiency of the system is better for such scenarios (see Figure 18).

4) Impact on vehicles total range: In the shortest path and fastest time scenarios the number of vehicles that run out of energy and have to stop before reaching the final destination is given in Table VI. In the same table, the mean value of the remaining energy is also shown. It is evident that the energy efficient scenario, based on the use of $M E D s$, gives better outcomes and balances the consumed energy of vehicles. These values are calculated for the default values of the system $\left(E_{t h}=6 \mathrm{~W}\right.$, Vehicle rate $\left.=1 / 5\right)$. Increasing the $E_{t h}$, or lowering the rate that vehicles are injected into the system, the improvement in the remaining energy of the vehicles is even greater.

\section{Intelligent $M E D s$}

An important aspect of cooperative mechanisms is increased awareness about the conditions in the neighborhood of a vehicle. $M E D s$ receive several charging requests from vehicles and respond with regards to availability on a First Come -

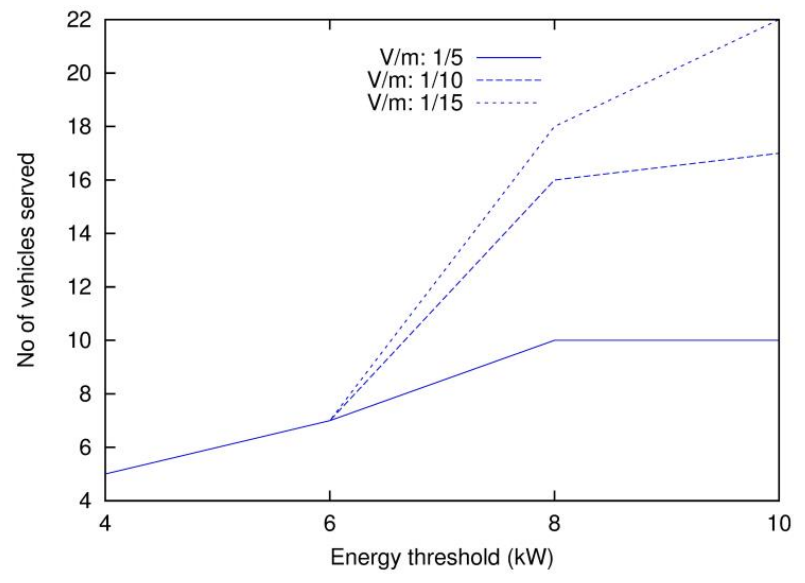

Fig. 18. Vehicles density affects system performance

TABLE VI

EVALUATION PERFORMANCE BASED ON REMAINING ENERGY $E$ OF VEHICLES WHEN REACHING THE TARGET NODE 9.

\begin{tabular}{|c|c|c|c|}
\hline Method & $\begin{array}{c}\text { No of Vehicles with } \\
\text { with } E_{\text {out }}<0\end{array}$ & $\begin{array}{c}\text { Mean } E_{\text {out }} \\
\mathrm{kWh}\end{array}$ & $\begin{array}{c}\text { Additional } \\
\text { range \% }\end{array}$ \\
\hline \hline Energy path & 0 & 10.186 & \\
\hline Shortest path & 4 & 9.07211 & $-11.8 \%$ \\
\hline Fastest path & 9 & 7.044 & $-44.03 \%$ \\
\hline
\end{tabular}

First Served basis without taking into account the real need of the vehicle requesting a booked place. This may lead to situations where vehicles with an immediate need for energy are unable to find a free booking place.

In order to cope with this problem, we modeled an enhanced mechanism where $M E D s$ decide to serve incoming requests based on the estimated additional energy that the vehicle will need in order to reach its destination. Vehicles, along with their request for energy, they also send the current energy level and their final destination. $M E D s$, using GPS and information about traffic on roads, can calculate the additional induced energy that each vehicle will need in order to reach its destination. . Based on this information, each $M E D$ can assess the level of importance of the requests, and serve those with greatest need, while declining to assist those with no real immediate requirements. The behaviour of the enhanced system is evaluated using the network with the two $M E D s$. All vehicles that send a request for recharging, also send information about their current energy level and final destination. With this information each $M E D$ decides whether to serve or decline the request.

In Figure 19, the impact of the cooperative mechanism on the systems performance is represented. In order to depict the differences in systems performance we inject vehicles at a lower rate $(1 / 10)$ and we set $E_{t h}$ equal to $10 \mathrm{~kW}$. The system now receives more requests for charging, while on the same time being able to meet most of them. The difference in the behaviour between the stand-alone and the cooperative mechanism lies in the appropriate selection of requests to be serviced. 


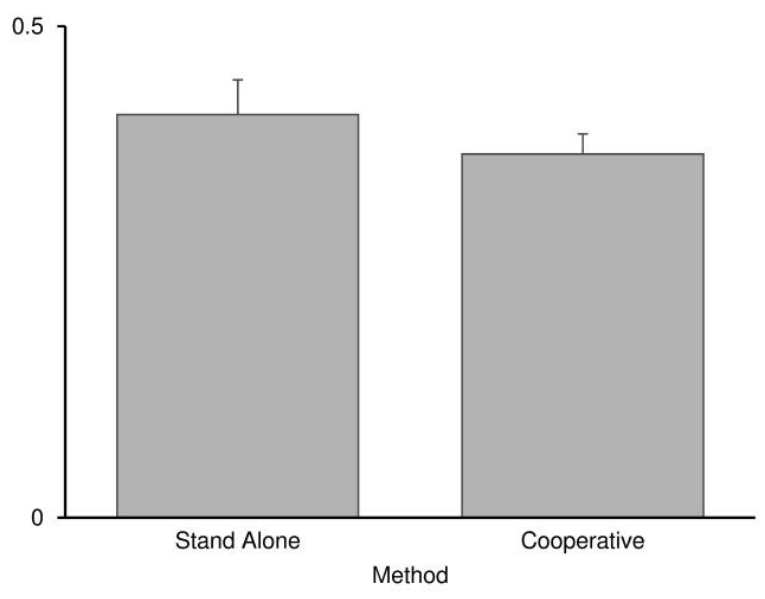

Fig. 19. Variance and standard deviation of parameter $E_{c}$

In order to represent this difference we calculate the mean and standard deviation of parameter $E c$, which is calculated using Equation 12. The calculated metric represents the proportion of energy consumed to the initial energy of the vehicle. We can observe from Figure 19 that with the cooperative mechanism both mean value and standard deviation are decreased.

$$
E_{c}=\frac{\text { Energy consumption }}{\text { Initial Energy }}
$$

\section{CONCLUSIONS}

In this article, we have demonstrated how mobile energy disseminators (MED) can facilitate EVs to extend their range in a typical urban scenario. Vehicles, based on several parameters, like time, energy and distance choose to follow longer but energy efficient paths. Making use of inductive charging $M E D s$ can act as mobile charging stations, thus improving the overall energy consumption of a fleet of vehicles. This improvement comes with a cost in time and distance traveled, but starving vehicles otherwise would have to stop or make longer re-routes in order to find a stationary station and recharge their batteries. Combining modern communications between vehicles and state of the art technologies on energy transfer, vehicles can extend their travel time without the need for large batteries or extremely costly infrastructure. Preliminary simulations show that applying some form of intelligence in how $M E D s$ take decisions about accepting or rejecting charging requests, further improves the performance of the method.

Our proposed method exploits $I V C$ communications in order to eco-route electric vehicles taking advantage of the existence of $M E D s$. In the future, more complex scenarios are going to be investigated where vehicles will have more charging options to choose from, both stationary and mobile. The combined use of $L T E$ and $D S C R$ capabilities is also going to be investigated, where vehicles will have the opportunity to communicate with a fleet of $M E D s$ and take more appropriate decisions based on less local information.

\section{REFERENCES}

[1] T. R. Hawkins, B. Singh, G. Majeau-Bettez, and A. H. Strmman, "Comparative environmental life cycle assessment of conventional and electric vehicles," Journal of Industrial Ecology, vol. 17, no. 1.

[2] H. de Wilde and P. Kroon, "Policy options to reduce passenger cars co2 emissions after 2020," 2013.

[3] S. Lukic and Z. Pantic, "Cutting the cord: Static and dynamic inductive wireless charging of electric vehicles," in Electrification Magazine, IEEE 2013, vol. 1, no. 1. pp. 57-64.

[4] N. Machiels, N. Leemput, F. Geth, J. Van Roy, J. Buscher, and J. Driesen, "Design criteria for electric vehicle fast charge infrastructure based on flemish mobility behavior," 2013.

[5] G. Putrus, P. Suwanapingkarl, D. Johnston, E. Bentley, and M. Narayana, "Impact of electric vehicles on power distribution networks," in Vehicle Power and Propulsion Conference, 2009. VPPC '09. IEEE, 2009.

[6] A. R. Mario, A. A. Fadi, M. Gagnaire, and Y. Lascaux, "Telewatt: An innovative electric vehicle charging infrastructure over public lighting systems," in Proceedings of the 2nd International Conference on Connected Vehicles and Expo (ICCVE), Las Vegas, USA, December, 2013.

[7] G. Jung, B. Song, S. Shin, S. Lee, J. Shin, Y. Kim, C. Lee, and S. Jung, "Wireless charging system for on-line electric bus(oleb) with seriesconnected road-embedded segment," in Environment and Electrical Engineering (EEEIC), 2013 12th International Conference on, 2013.

[8] L. A. Maglaras, F. V. Topalis, and A. L. Maglaras, "Cooperative approaches for dymanic wireless charging of electric vehicles in a smart city," in Energy Conference (ENERGYCON), 2014 IEEE International, May 2014, pp. 1365-1369.

[9] K. Boriboonsomsin, M. J. Barth, W. Zhu, and A. Vu, "Eco-routing navigation system based on multisource historical and real-time traffic information," 2012.

[10] L. A. Maglaras, P. Basaras, and D. Katsaros, "Exploiting vehicular communications for reducing co2 emissions in urban environments," in in proceedings of the IEEE International Conference on Connected Vehicles (ICCVE 2013), Las Vegas, USA, December 2-6, 2013.

[11] L. Zi-fa, Z. Wei, J. Xing, and L. Ke, "Optimal planning of charging station for electric vehicle based on particle swarm optimization," in Innovative Smart Grid Technologies - Asia (ISGT Asia), 2012.

[12] M. Badawy, N. Arafat, S. Anwar, A. Ahmed, Y. Sozer, and P. Yi, "Design and implementation of a $75 \mathrm{kw}$ mobile charging system for electric vehicles," in Energy Conversion Congress and Exposition (ECCE), 2013 IEEE, 2013.

[13] S. Deilami, A. Masoum, P. Moses, and M. A. S. Masoum, "Realtime coordination of plug-in electric vehicle charging in smart grids to minimize power losses and improve voltage profile," Smart Grid, IEEE Transactions on, 2011.

[14] K. Mets, T. Verschueren, W. Haerick, C. Develder, and F. De Turck, "Optimizing smart energy control strategies for plug-in hybrid electric vehicle charging," in Network Operations and Management Symposium Workshops (NOMS Wksps), 2010 IEEE/IFIP, 2010.

[15] S. Bohn, M. Agsten, O. Waldhorst, A. Mitschele-Thiel, D. Westermann, and P. Bretschneider, "An ict architecture for managed charging of electric vehicles in smart grid environments," in Journal of Engineering, 2013.

[16] D. Promiti, "Coordinating rendezvous points for inductive power transfer between electric vehicles to increase effective driving distance," in Proceedings of the 2nd International Conference on Connected Vehicles and Expo (ICCVE), Las Vegas, USA, December, 2013.

[17] C. Donna, M. K. Kara, and K. Moby, "The electric vehicle charging station location problem: A parking-based assignment method for seattle," in Proceedings of the 92nd Annual Meeting of the Transportation Research Board, 2013.

[18] I. Frade, A. Ribeiro, G. Goncalves, and A. Antunes, "Optimal location of charging stations for electric vehicles in a neighborhood in lisbon, portugal," in Transportation Research Record: Journal of the Transportation Research Board, No. 2252: 91-98, 2011.

[19] M. R. Sarker, H. Pandzic, and M. A. Ortega-Vazquez, "Electric vehicle battery swapping station: Business case and optimization model."

[20] M. Neaimeh, G. Hill, Y. Hubner, and P. Blythe, "Routing systems to extend the driving range of electric vehicles," Intelligent Transport Systems, IET, vol. 7, no. 3, pp. 327-336, 2013.

[21] L. A. Maglaras and D. Katsaros, "Distributed clustering in vehicular networks," in Wireless and Mobile Computing, Networking and Com- 
munications (WiMob), 2012 IEEE 8th International Conference on, Oct 2012.

[22] N. Lagraa, M. B. Yagoubi, S. Benkouider et al., "Localization technique in vanets using clustering (lvc)," IJCSI, 2010.

[23] M. Segata, F. Dressler, R. Lo Cigno, and M. Gerla, "A simulation tool for automated platooning in mixed highway scenarios," in Proceedings of the 18th annual international conference on Mobile computing and networking. ACM, 2012, pp. 389-392.

[24] L. A. Maglaras, J. Jiang, F. V. Topalis, and A. L. Maglaras, "Mobile energy disseminators increase electrical vehicles range in smart city," in Hybrid and Electric Vehicle Conference, IET, November 2014. 